\title{
SIMULAÇÃO DE PACIENTES - CURSOS DE SUPORTE DE VIDA ACLS, BLS E PALS NA FMRP - USP
}

\author{
PATIENT SIMULATION: LIFE SUPPORT COURSES ACLS, BLS AND PALS IN \\ THE MEDICAL SCHOOL OF RIBEIRÃO PRETO OF THE UNIVERSITY OF SÃO PAULO
} Antonio Pazin Filho ${ }^{1}$, André Schmidtt ${ }^{1}$ Cleide Filipini², Renato Barroso Pereira de Castro ${ }^{3}$, Rita Márcia Rosa ${ }^{4}$,
Maria Alice Oliveira Ferreira da Rosa ${ }^{4}$ Cláudia Dizioli Franco Bueno $^{5}$, Benedito Carlos Maciel ${ }^{1}$

${ }^{2}$ Docente. Departamento de Clínica Médica. ${ }^{2}$ Ex Coordenadora Administrativa. Centro de Aperfeiçoamento Profissional em Saúde CEAPS. ${ }^{3}$ Médico Assistente.Departamento de Clínica Médica. ${ }^{4}$ Enfermeira. Divisão de Enfermagem do HCFMRP-USP. Faculdade de Medicina de Ribeirão Preto - USP. ${ }^{5}$ Médica.

Correspondência: Prof.Dr. Antonio Pazin Filho (apazin@fmrp.usp.br). Centro de Estudos de Emergências em Saúde - CEES. Rua Bernardino de Campos, 1000. 14015-030 Ribeirão Preto - SP.

Pazin Filho A, Schmidt A, Filipini C, Castro RBP, Rosa RM, Rosa MAOF, Bueno CDF, Maciel BC. Simulação de pacientes - cursos de suporte de vida ACLS, BLS e PALS na FMRP- USP. Medicina (Ribeirão Preto) 2007; 40 (2): 204-12.

Resumo: Os cursos de suporte de vida organizados e coordenados pela American Heart Association incluem as modalidades: Suporte Básico de Vida, Suporte Avançado de Vida em Cardiologia e Suporte de Vida Avançado em Pediatria. Esses cursos estão sendo disseminados mundialmente, especialmente após o estabelecimento de diretrizes internacionais estabelecendo consensos para o atendimento a emergências clínicas. O impacto da inserção destes cursos em instituições universitárias brasileiras ainda é desconhecido. O objetivo precípuo deste artigo é descrever a experiência de implantação de um centro de treinamento em Suporte de Vida no Hospital das Clínicas da Faculdade de Medicina de Ribeirão Preto da Universidade de São Paulo (HCFMRP-USP), um hospital universitário público inserido no Sistema Único de Saúde. São discutidos aqui aspectos históricos, financiamento e gerenciamento, o impacto em atividades de pesquisa, ensino e de atenção à saúde tanto no contexto local, regional, nacional e internacional, bem como suas perspectivas futuras.

Descritores: Suporte Avançado a Vida. Cursos. Educação Médica.

\section{1- INTRODUÇÃO}

Os cursos de suporte de vida (Life Support) foram introduzidos no Brasil há mais de 14 anos, como resultado de iniciativa pioneira da Sociedade Brasileira de Cardiologia (SBC) por meio da Fundação do Coração (FunCor) . Considerando que o curso de Suporte Avançado de Vida em Trauma - Advanced Trauma Life Support (SAVT - ATLS) foi o primeiro a ser introduzido no Brasil, é comum confundí-lo com os cursos patrocinados pela American Heart Association
(AHA). Neste artigo, compreende-se por cursos de Suporte de Vida os cursos de Suporte Básico de Vida - Basic Life Support (SBV - BLS), Suporte de Vida Avançado em Cardiologia - Advanced Cardiac Life Support (SAVC - ACLS) e Suporte Avançado de Vida em Pediatria -Pediatric Advanced Life Support (SAVP - PALS) cujo escopo e público-alvo são resumidos na Tabela I, enquanto sua estrutura é sumarizada em outro artigo deste simpósio. Estes cursos de treinamento são oferecidos por centros constituídos de modo independente, mas que são vinculados 
Tabela I - Descrição dos cursos de suporte de vida

\begin{tabular}{lll}
\hline Tipo de curso de suporte de vida & Objetivos & População-alvo \\
\hline Suporte Básico de Vida & Massagem cardíaca externa - todas & - População leiga em geral \\
"Basic Life Support" & as faixas etárias & - Profissionais da área de saúde \\
(SBV/BLS) & - Respiração substitutiva & \\
& (boca-a-boca; boca-nariz; boca- \\
& estoma) - todas as faixas etárias \\
& - Desfibrilação externa automática \\
& - Manuseio de situações de corpo es- \\
& tranho
\end{tabular}

Suporte Avançado de Vida em Cardiologia

"Advanced Cardiac Life Support" (SAVC/ACLS)
- Massagem cardíaca externa - adultos

- Respiração substitutiva - adultos

- Manutenção invasiva de via aérea (entubação oro-traqueal)

- Desfibrilação externa automática e manual

- Situações emergenciais que podem evoluir para parada cardíaca - distúrbios do ritmo cardíaco

- Situações emergenciais que requerem diagnóstico e intervenção rápidos - Síndromes Coronarianas Agudas e Acidente Vascular Encefálico

Suporte Avançado de Vida em Pediatria

"Advanced Pediatric Life Support" (SAVP/PALS)
- Massagem cardíaca externa

- Respiração substitutiva

- Manuseio invasivo de via aérea

- Desfibrilação automática e manual
- Profissionais da área de saúde*

- Profissionais da área de saúde*

* No Brasil, por definição do Conselho Federal de Medicina, os procedimentos de desfibrilação externa manual e manuseio de vias aéreas são reservados para o profissional médico. Aos outros profissionais da área de saúde, é facultada a participação no curso e o ensino de princípios de utilização destas técnicas, mas é vedado a sua execução.

hierarquicamente a uma central nacional, uma central continental e em última instância, à AHA, com sede nos Estados Unidos ${ }^{1}$.

A experiência brasileira é apenas mais uma, no amplo contexto de disseminação mundial do oferecimento destes cursos, na última década, especialmente quando se considera a padronização universal de diretrizes para atendimento clínico de emergência, que contou com a contribuição de especialistas de diversos países, incluindo o Brasil $^{2}$. Trata-se da primeira inicia- tiva mundial de padronização, o que implica em generalização facilmente adaptável quando se trata da transmissão uniforme de conceitos, mas que apresenta limitações quando se procura preconizar práticas para serviços de saúde com organização estrutural e complexidade distintas ${ }^{3,4,5}$. Esta limitação pode se estender para os métodos de treinamento, que podem estar sujeitos a aspectos culturais, constituindo barreiras para as quais se têm poucos dados disponíveis.

A inserção destes cursos na realidade brasilei- 
ra tem sido empreendida mediante criação de centros de treinamento em diversas localidades, com vinculação a instituições universitárias, associações médicas ou a instituições privadas ${ }^{5}$. O objetivo deste artigo é descrever a experiência de implantação de um centro de treinamento em Suporte de Vida no Hospital das Clínicas da Faculdade de Medicina de Ribeirão Preto da Universidade de São Paulo (HCFMRP-USP), discutindo aspectos históricos, financiamento e gerenciamento, seu impacto nas atividades de pesquisa, ensino e de atenção à saúde tanto no contexto local, regional, nacional como internacional, bem como suas perspectivas futuras.

\section{2- ASPECTOS HISTÓRICOS DA IMPLANTA- ÇÃO E REPRESENTATIVIDADE DO CEN- TRO DE TREINAMENTO}

O projeto de instalação do centro de treinamento da FMRP-USP pela Divisão de Cardiologia estava plenamente integrado com a criação Centro de Dor Torácica na Unidade de Emergência (UE) do HCFMRP-USP. O passo inicial nessa direção foi dado no mês de setembro de 1998, quando a Divisão de Cardiologia ofereceu a dois médicos assistentes a ela vinculados a oportunidade para realizar o curso regular de provedor (aluno) de SAVC. Esse processo teve prosseguimento com mais dois médicos da Divisão realizando o mesmo curso, em novembro de 1998, e culminou com o primeiro curso de SAVC realizado pela Divisão de Cardiologia, em Ribeirão Preto, em janeiro de 1999, ao qual se seguiu um curso de instrutor, no qual médicos assistentes e docentes realizaram a formação inicial para ministrar cursos. Completada esta fase inicial, houve um intervalo de cerca de seis meses até a realização do segundo curso de SAVC em Ribeirão Preto (julho de 1999). Durante esse período foram adquiridos os equipamentos e materiais necessários para que o Centro de Treinamento conquistasse sua autonomia, ao mesmo tempo em que o treinamento prático de outros membros da equipe da Cardiologia, como instrutores em cursos realizados pelo FunCor em diversas localidades do país, foi empreendido.
Para a aquisição do material e gerenciamento financeiro, estabeleceu-se acordo com a Fundação de Apoio ao Ensino, Pesquisa e Assistência (FAEPA) do Hospital das Clínicas da Faculdade de Medicina de Ribeirão Preto, que proporcionou o financiamento inicial, recebendo, como contrapartida, uma participação na arrecadação dos cursos, além da reposição parcelada do investimento inicial. A participação da Fundação de Apoio foi também fundamental para agilizar a aquisição dos equipamentos importados que compunham o material necessário para os cursos. Esta fase foi concluída com a realização do segundo curso de SAVC em Ribeirão Preto, já com o material adquirido pelo Centro de Treinamento, em julho de 1999.

Em que se pese o valor significativo investimento inicial realizado, o compromisso de ressarcimento desse investimento assumido com a FAEPA foi cumprido integralmente em menos de dois anos, como resultado do elevado número de cursos oferecidos desde então (Figura 1), bem como do rigoroso controle financeiro empreendido.

A experiência com a implantação dos cursos de SAVC foi utilizada e reproduzida para a instalação dos cursos de SBV (setembro de 2000) e SAVP (fevereiro de 2002), pela Divisão de Enfermagem do HCFMRP-USP e pelo Departamento de Pediatria da FMRP-USP, respectivamente. Com o estabelecimento destes dois novos cursos, consolidou-se a constituição

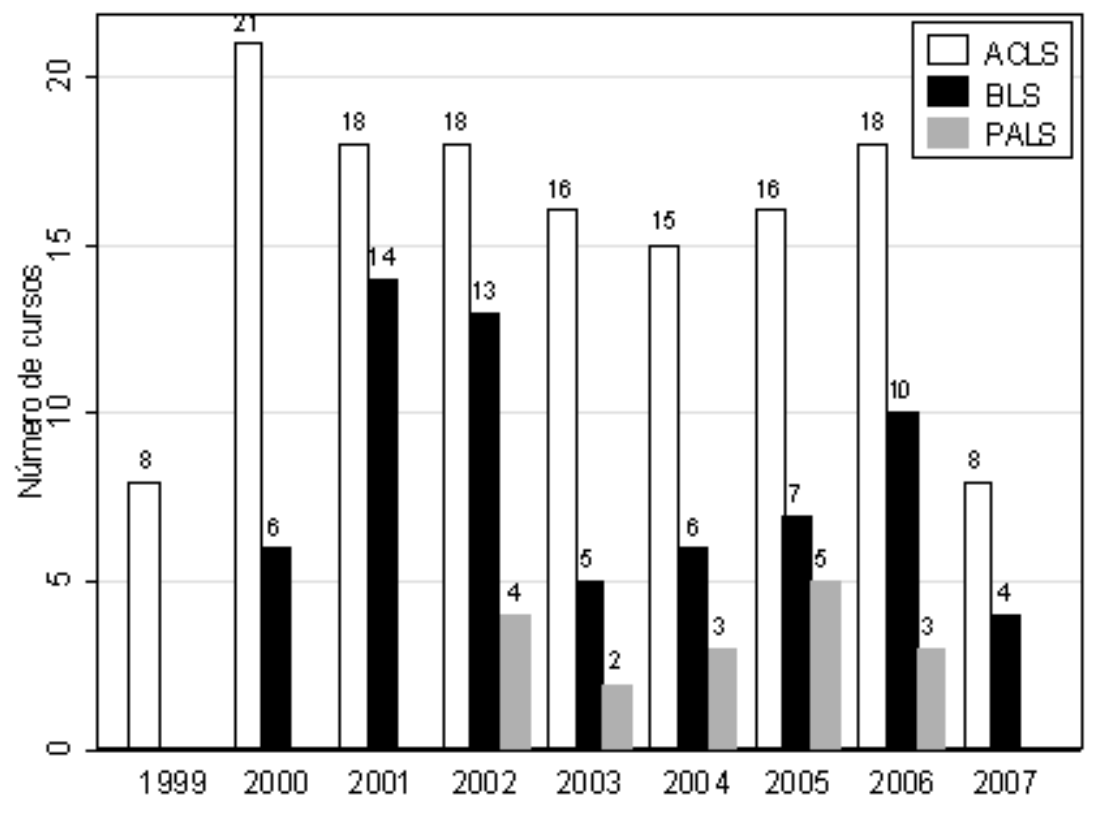

Figura 1: Distribuição do número de cursos realizados pelo Centro de Treinamento em Suporte de Vida do HC-FMRP-USP de acordo com o tipo de curso e ano desde a sua criação até a presente data. 
do Centro de Treinamento, o que permitiu, a seguir, a inserção desta nova instituição em âmbito nacional e internacional.

Desde o início de suas atividades, este Centro de Treinamento teve entre seus objetivos a busca de representatividade junto a instituições nacionais e internacionais que coordenam esses programas. No plano nacional, foram estabelecidas relações funcionais tanto com o FunCor quanto com o Conselho Nacional de Ressuscitação nos períodos em que estas instituições mantinham a representação nacional destes cursos, embora atualmente inexista uma coordenação centralizada desses programas. No plano internacional, houve inicialmente o vínculo indireto através da representação brasileira, mas, recentemente, foi conseguida a vinculação direta à AHA, sendo que o Centro de Treinamento do HCFMRP-USP se constituiu num dos três primeiros centros brasileiros a serem reconhecidos internacionalmente.

Todos estes cursos foram organizados e estão sediados no Centro de Ensino e Aperfeiçoamento Profissional em Saúde (CEAPS) do HCFMRP-USP, que desde o princípio assumiu a estrutura administrativa dos cursos, provendo área física e a equipe de secretaria necessária para o desenvolvimento dos cursos.

A estrutura montada promoveu a realização de número substancial de cursos ao longo dos quase 8 anos de funcionamento, o que é ilustrado na Figura 1. Além disto, estes cursos foram realizados não só nas dependências do CEAPS, como também em diversas localidades no interior do Estado de São Paulo (Figura 2) e no Brasil (Figura 3).

\section{3- ENSINO DE GRADUAÇÃO E PÓS-GRA- DUAÇÃ O}

Os cursos da AHA são baseados em ensino por tarefas, utilizando técnicas de simulação em manequins, bem como outros métodos, como o ensino

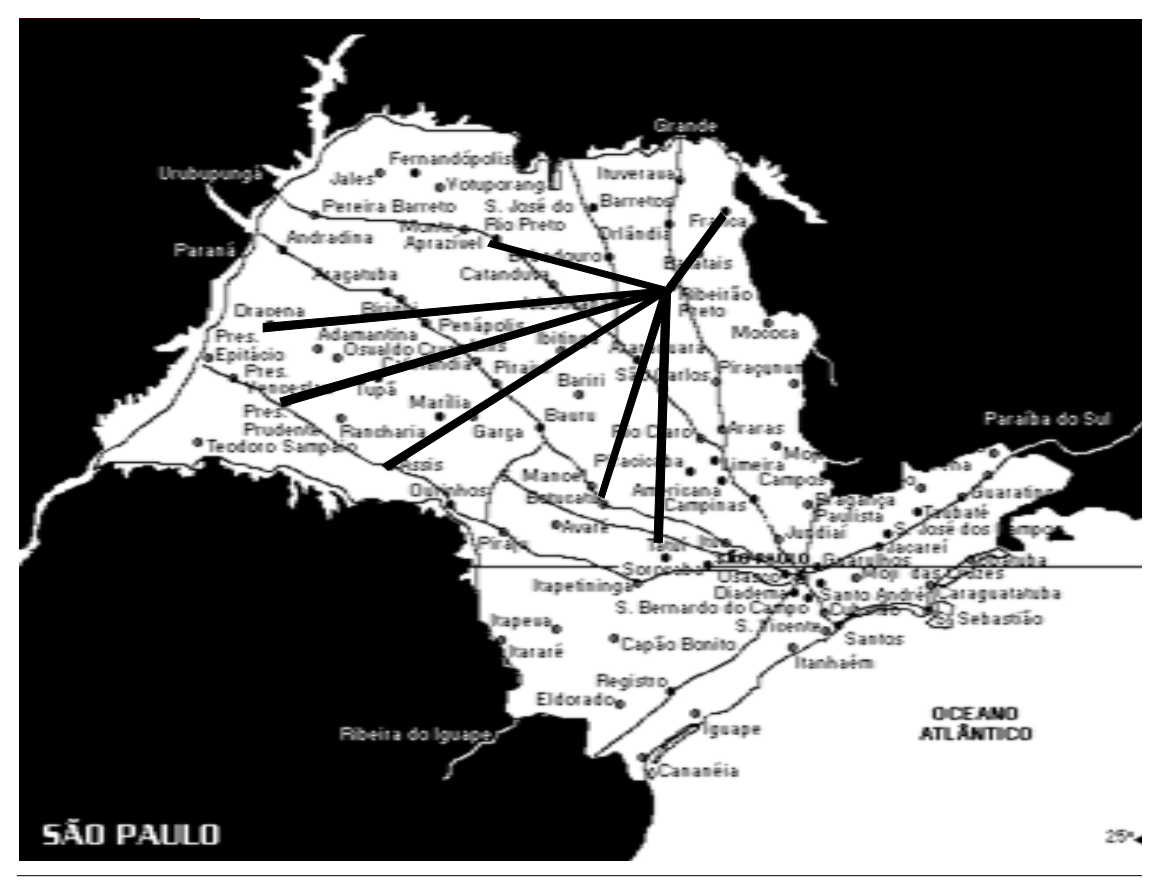

Figura 2: Localidades do Estado de São Paulo nas quais o Centro de Treinamento do HC-FMRP-USP realizou cursos de Suporte de Vida.

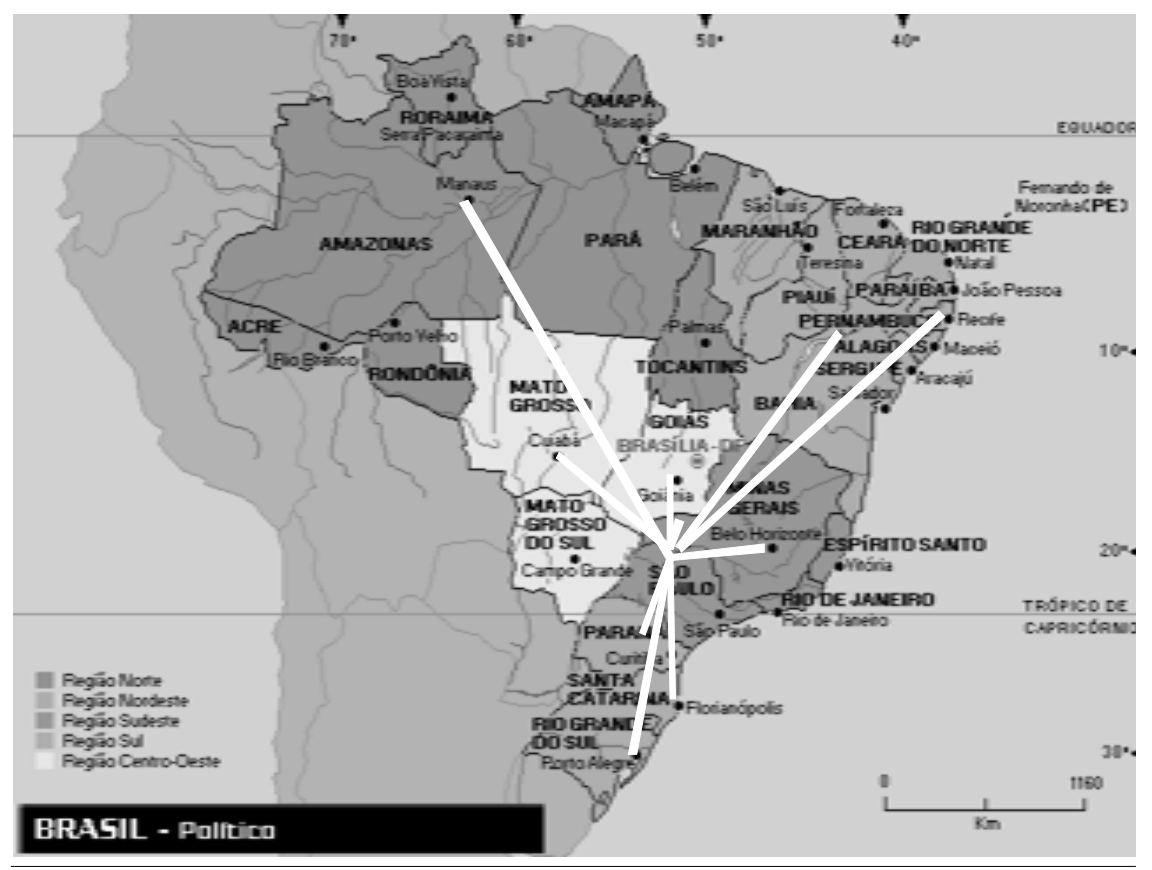

Figura 3: Localidades fora do Estado de São Paulo nas quais o Centro de Treinamento do HC-FMRP-USP realizou cursos de Suporte de Vida. 
baseado em vídeo e o "peer-to-peer review" (atividade durante a qual o aluno realiza as manobras ministradas, sendo corrigido pelos próprios companheiros, sob supervisão à distância de um instrutor, que intervém apenas quando necessário). Estas técnicas visam a contornar as limitações inerentes ao ensino com aulas teóricas formais no aprendizado de habilidades psicomotoras ${ }^{6}$. O caráter repetitivo dos cursos, que sempre seguem um mesmo padrão de abordagem dos problemas propostos, oferece uma condição ímpar para observação do comportamento tanto de alunos como de instrutores, o que propiciou uma experiência transposta para o ensino de pós-graduação mediante a criação de uma disciplina sobre Didática em Aulas Teóricas Formais, que obteve elevada aceitação entre os alunos de pós-graduação e que culminou com um simpósio para avaliação do tema ${ }^{7}$. Essa experiência também propiciou o desenvolvimento de um projeto de pesquisa na área de Didática ${ }^{8}$, com o objetivo de identificar necessidades dos alunos de pós-graduação no preparo de aulas teóricas e, ainda, servindo como base para a criação de uma outra disciplina, recentemente aprovada pela Comissão de Pós-Graduação da FMRP-USP.

O impacto desses cursos sobre o ensino de graduação da FMRP-USP também foi bastante significativo. Isso ocorreu, primeiramente, quando a Divisão de Cardiologia introduziu técnicas de ensino de simulação, utilizando o material adquirido pelo centro de treinamento, na abordagem de parada cardiorrespiratória (PCR), em disciplina ministrada no quarto ano do curso de Medicina. Posteriormente, os conceitos de atendimento de PCR também passaram a ser ensinados por técnicas de simulação, utilizando o material adquirido para esses cursos, no sexto ano do curso de Medicina e, mais recentemente, no primeiro ano de graduação em Fisioterapia.

Estas iniciativas ocorreram dentro do espaço alocado para cursos já instalados, não implicando em custos adicionais aos programas de ensino de graduação da FMRP-USP. Inovação adicional ocorreu com a inserção dos conceitos de PCR para suporte básico de vida no segundo ano do curso de Medicina, com a criação da disciplina de Primeiros Socorros, na qual também se utiliza do material do Centro de Treinamento.

Embora a utilização dessas técnicas de ensino com simulação seja objeto de grande aceitação entre os alunos de graduação, ao contrário da experiência vivenciada na pós-graduação ${ }^{8}$, que já proporcionou dados quantitativos para avaliação objetiva desse processo, a experiência na graduação ainda carece de avaliação mais sistematizada.

\section{4- ASSISTÊNCIA À SAÚDE E EXTENSÃO DE SERVIÇOS À COMUNIDADE}

Considerando que um dos objetivos fundamentais de um centro de treinamento que ofereça cursos de Suporte de Vida é proporcionar à comunidade médica e a outros profissionais de saúde treinamento de qualidade elevada em habilidades psicomotoras específicas, seu impacto sobre a atenção à saúde da população pode ser, em um primeiro momento, ser aquilatado pelo número de cursos oferecidos por esse Centro tanto para a comunidade local, como regional e nacional. Como mostra a Figura 1, fica evidente que o Centro de Treinamento da FMRP-USP ofereceu um elevado número de cursos, desde sua implantação. Nesse período, os 220 cursos já ministrados contaram com a participação de 5344 médicos ou outros profissionais de saúde. Inequivocamente, essa participação teve reflexos importantes na qualidade do atendimento que esses profissionais ofereçam aos seus pacientes.

Tendo em vista que esses cursos possuem uma estruturação organizacional auto-sustentável, suas atividades de extensão de serviços à comunidade são empreendidas sem impor qualquer custo para o HCFMRP-USP. Pelo contrário, a locação dos espaços do Hospital para a realização dos cursos representa uma fonte adicional de recursos que a FAEPA utiliza para investir em outras atividades do Hospital.

Impacto qualitativo importante para o $\mathrm{HC}$ FMRP-USP é decorrente do fato de que vários dos alunos treinados nestes cursos são residentes da instituição. O treinamento uniformizado provido pelos cursos se reflete na qualidade do atendimento padronizado proporcionado pelas equipes de atendimento de urgência da instituição. Este benefício deve ser incrementado ainda mais com a reestruturação da Equipe de PCR do HC-FMRP-USP, atualmente em fase de implantação, que prevê a extensão subsidiada deste treinamento para residentes de primeiro ano, permitindo que a instituição se beneficie por maior tempo deste investimento. Esta sistemática também preve a reestruturação não só do treinamento da equipe, como também das condições de atendimento, com aquisição de equipamento e logística de atendimento e documentação para melhoria continuada do processo. 
Demonstração adicional da importância desses cursos para a assistência à saúde da população pode ser evidenciada pela experiência de extensão dessas atividades de ensino para um programa de atendimento de PCR em ambiente pré-hospitalar para leigos ${ }^{9}$. O Centro de Treinamento, com base na experiência adquirida com o SBV, iniciou contato maior com a comunidade leiga, realizando cursos de treinamento em massa ("Mass Training") - Figura 4. Estes cursos são estruturados de forma mais simplificada para facilitar a retenção dos conceitos sobre atendimento de PCR e medidas preventivas de fatores de risco cardiovascular, uma vez que eles são ministrados a leigos utilizando ensino baseado em vídeos e simulação em manequins. Exatamente por essas características, os manequins utilizados são menos complexos dos que os utilizados para os cursos para profissionais de saúde, mesmo porque estes cursos envolvem o treinamento simultâneo de quase uma centena de pessoas, enquanto os cursos ministrados para profissionais de saúde envolvem a participação de aproximadamente vinte alunos.

Ainda dentro deste âmbito de extensão de serviços para a comunidade, o centro também realizou cursos para instituições recreativas da cidade de Ribeirão Preto interessadas em introduzir recursos de desfibrilação automática requisitados por legislação pertinente.
A ênfase na avaliação de habilidades psicomotoras preconizada pela Comissão Nacional de Residência, além da avaliação cognitiva, nos processos seletivos dos programas de Residência Médica resultou no envolvimento dos recursos do Centro de Treinamento nos exames realizados no HCFMRP-USP, o que foi facilitado pela disponibilidade destes recursos na instituição. A avaliação objetiva do impacto desta atividade ainda depende de um número mais elevado de observações sobre sua aplicação.

Além desses aspectos, o centro tem procurado discutir com as autoridades competentes as dificuldades e limitações no atendimento à PCR pré-hospitalar, propondo medidas que possam aprimorar a qualidade deste atendimento. $\mathrm{O}$ reconhecimento pelo Conselho Regional de Medicina do Estado de São Paulo, da desfibrilação automática como atividade que pode ser executada por leigos, desde que treinados para tanto, é um exemplo da atuação do centro de treinamento. Finalmente, não pode deixar de ser considerado que, embora esses cursos tenham suas atividades desenvolvidas sempre aos finais de semana e imponham às equipes de instrutores sobrecarga significativa de trabalho em dias habitualmente dedicados ao descanso, a participação de médicos assistentes do HCFMRP-USP, vinculados à Divisão de Cardiologia, representa para esses profissionais uma oportunidade de aumentar um

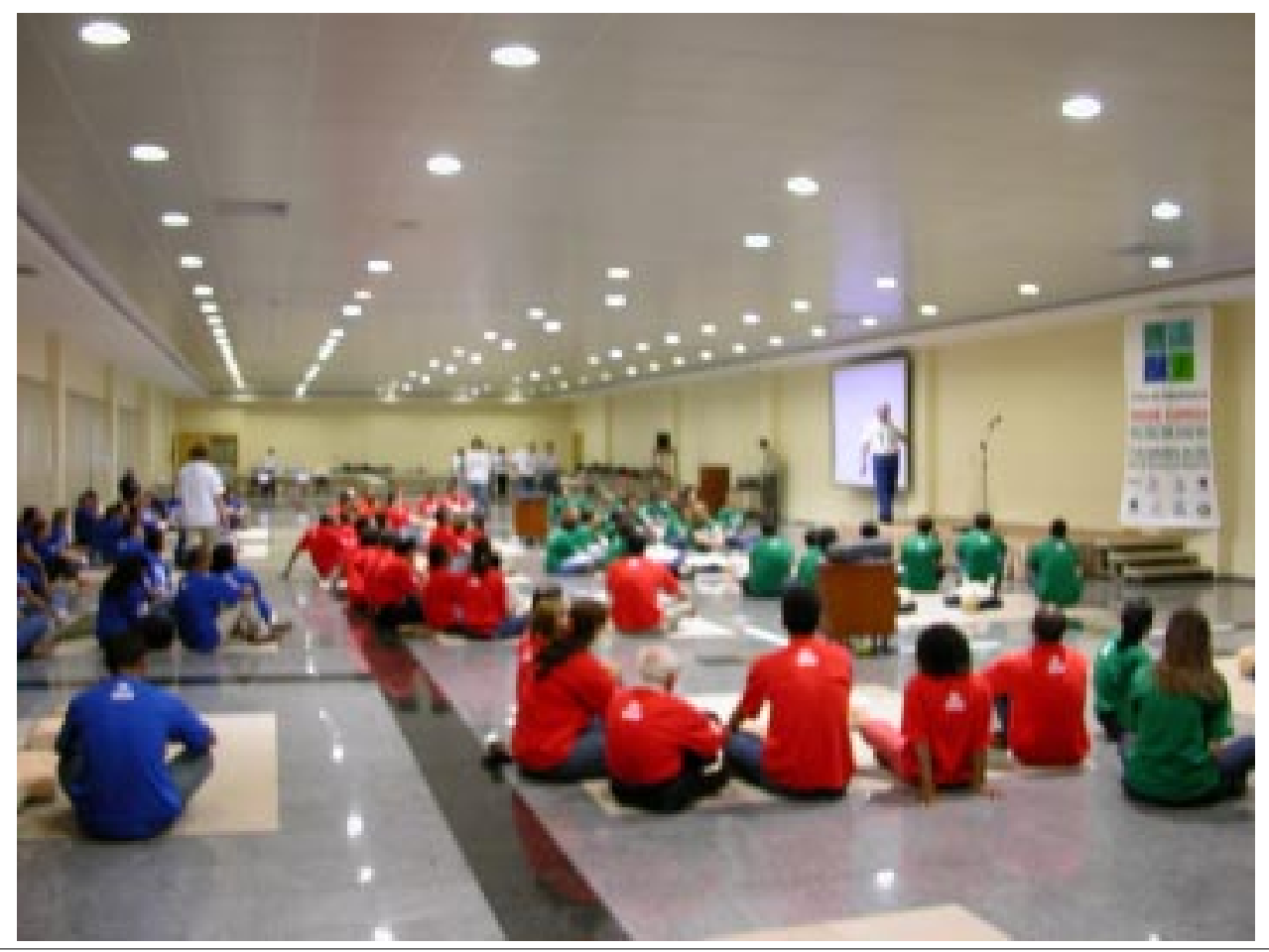

Figura 4: "Treinamento em massa" - extensão à comunidade 
pouco sua remuneração mensal, uma vez que os salários desses profissionais no sistema público não são atrativos nem competitivos. De certa forma, a instituição hospitalar e universitária a que eles estão vinculados aufere benefícios indiretos dessa atuação, já que essa remuneração adicional, por mais perverso que possa ser esse mecanismo, contribui para a manutenção do vínculo institucional de uma equipe de profissionais altamente especializados, engajados e competentes.

\section{5- PESQUISA}

O desenvolvimento de pesquisa em PCR e ensino por simulação são áreas de difícil inserção, haja vista a inexistência de um modelo experimental reconhecidamente adequado, as limitações éticas para as intervenções em humanos e a inexistência de muitas informações que possam dar embasamento a novas hipóteses de trabalho ${ }^{10 / 14}$. Neste contexto, o desenvolvimento de pesquisa local em PCR enfrentou dificuldades. Muito embora o desenvolvimento de pesquisa na área tenha sido uma das metas, desde a implantação do centro, as atividades de investigação só foram iniciadas depois que as atividades do centro de treinamento estavam consolidadas.

Um primeiro exemplo do envolvimento em pesquisa foi a associação com outros centros de treinamento, visando à avaliação do impacto dos cursos de suporte de vida na sobrevida de pacientes atendidos com PCR intra-hospitalar ${ }^{15}$. Este estudo, realizado em conjunto com mais quatro centros brasileiros, foi um dos primeiros a demonstrar o impacto positivo do método, até então especulativo.

No mesmo molde de cooperação, a participação do centro de treinamento em reuniões e congressos nacionais e internacionais motivou artigos de revisão ${ }^{16 / 20}$ e capítulos de livro sobre o tema ${ }^{21}$, bem como a participação na elaboração do material a ser fornecido nos cursos de treinamento ${ }^{22}$.

O maior desafio, no entanto, foi o envolvimento em pesquisa local, que se desenvolveu em duas áreas de atuação. A primeira constituída por uma linha de epidemiologia clínica, caracterizada pela distribuição na população atendida pela UE-HCFMRP-USP por PCR e por distúrbios do ritmo cardíaco, enquanto uma segunda frente de trabalho foi aberta na área de didática, motivada pelo processo de treinamento dos cursos. No que tange à epidemiologia clínica, os primeiros frutos foram decorrentes do perfil dos pacientes atendidos com PCR na UE, que foram o embasamento para a reestruturação do sistema de atendimento de PCR no HC-FMRP-USP e já motivou tese de mestrado $^{23}$ e divulgação no plano nacional ${ }^{24,25}$. Desta primeira experiência bem sucedida, também se origina a continuação de processo de pós-graduação em tese de doutoramento a ser desenvolvida para avaliação do processo de reestruturação do sistema de atendimento intra-hospitalar de PCR do HC-FMRP-USP. Na mesma linha de epidemiologia clínica, a caracterização do impacto da função ventricular na apresentação clínica de pacientes com distúrbio do ritmo cardíaco atendidos na UE-HC-FMRP-USP é tema de dissertação de mestrado em andamento ${ }^{26}$, que já gera os primeiros frutos.

\section{6- DESAFIOS E OBJETIVOS FUTUROS}

Em que se pese a experiência positiva descrita, muitas barreiras ainda devem ser vencidas.

Um primeiro aspecto diz respeito ao treinamento e manutenção de instrutores para os cursos. O grande número de cursos realizados requer pessoal capacitado por treinamento exaustivo. A grande maioria dos instrutores não são membros do corpo docente da FMRP-USP que trabalham em regime de dedicação exclusiva e desenvolvem outras atividades que muitas vezes limitam a sua participação continuada. A reposição do pessoal é demorada e muitas vezes o que se consegue remunerar é insuficiente para reter o instrutor por tempo prolongado, ainda mais quando associado ao desgaste de viagens durante os finais de semana quando os cursos são realizados. Alternativas para contornar esta limitação ainda não podem ser antevistas e esbarram em obrigações trabalhistas de elevado custo financeiro.

A inserção destes cursos nos cursos de pósgraduação foi tranqüila em virtude do caráter de nãoobrigatoriedade. Já a inserção destes cursos na graduação e no programa de residência médica do HCFMRP-USP, requer a discussão frente aos objetivos das instituições e são limitados em muitas ocasiões por custos e disponibilidade de material, bem como pelo reconhecimento do esforço docente com o envolvimento nesta sistemática de ensino. Iniciativas como as descritas neste simpósio podem favorecer que esta inserção seja otimizada nos próximos anos.

Em virtude da atual tendência do ensino médico de utilizar a simulação como forma de preparar de modo mais consistente o aluno antes de expô-lo a situações reais, há interesse em agregar outras experi- 
ências incipientes na Faculdade de Medicina de Ribeirão Preto - USP em um grupo coordenado. Dessa forma, será possível estimular a implantação e utilização de técnicas de simulação em diversas áreas dos cursos voltados para a saúde existentes no Campus da Ribeirão Preto da Universidade de São Paulo.

As iniciativas em pesquisa devem se estender nos próximo anos, aproveitando-se das experiências iniciais. O desafio consistirá não só no desenvolvimento de projetos locais, bem como na inserção em projetos epidemiológicos multicêntricos necessários para o teste de grandes hipóteses.

\section{7- AGRADECIMENTOS}

A realização dos cursos não seria possível sem a participação de inúmeras pessoas.

Aos Senhores: Luiz Antonio Paoliello Factore, Dario Fortes Ferreira, Miguel Antonio Moretti e Amélia Reis, responsáveis pela formação dos primeiros instrutores em nosso Centro e por muitos anos nossa referência na resolução de problemas.

Aos funcionários do CEAPS: Anderson Luiz Jacob de Almeida; Cleide Filipini; Cristina Dias Esteves Forli; Fabiana Maria Cocenza Ponsoni Correa de Melo; Francisco Junio Leopoldino; Fulvio da Silva; Helena Saldanha e Silva; Janice Del Lama Miquelim; José Carvalho dos Santos; Kenneth Fernandes Oliveira; Régis Bencsik Montero; Sirlene Chaves Batista; Vivianne Marcondes Laranjeira.

Aos instrutores:

ACLS: Adriana Cristina Moreno; André Schmidt; Antonio Pazin Filho; David José Oliveira Tozetto; Denise Rodrigues Schmidt; Eduardo Mendel Balbi Filho; Fábio de Paula Turco; Fábio Fernandes Neves; Fernando Bruetto Rodrigues; Giancarlo Gonçalves; Gilmar Valdir Greque;
Gustavo Carvalho; José Carlos dos Santos; José Rafael Vieira Júnior; João Lucas O' Connell; Leandro Carlos Resende Bazon, Leon Gustavo dos Reis Macedo; Luciano Henrique Melato; Marcos de Carvalho Borges; Minna Moreira Dias Romanno; Octávio Marques Pontes Neto; Osvaldo Merege Vieira Neto; Paula Menezes Luciano; Rafael Carlos Miranda; Renato Barroso Pereira de Castro; Ricardo Augusto Goulart; Roberto Minoru Tani Inowe; Rodrigo Siqueira de Abreu e Lima; Sérgio Luiz Brasileiro Lopes; Telêmaco Luiz da Silva Júnior; Thiago Florentino Lascala; Vamberto Benedito Mansur Foschini.

BLS: Adriana Cristina Moreno; Adriana de Fátima Manoel; Ana Beatriz Fernandes Ferreira; André Schmidt; Angela Rosa da Silva; Antonio Pazin Filho; Carlos Fernando Pereira Da Silva Herrero; Cesar Augusto Giovanni Braga; Cesar Eduardo Pedersoli; Daniela Santos Danielli; Denise Rodrigues Schmidt; Edmar Porfírio de Oliveira; Helem Maira Pupin Monteiro; Ilka Barbosa Pegoraro; José Carlos dos Santos; Juliana Cardeal da Costa; Juliana Pereira Machado ; Karina Dal Sasso; Leonice Maria Saladini Marques dos Santos; Lisandra Maria Baptista; Lucinéia Alves Pereira; Madalena Rosana Martins; Maria Alice Oliveira Ferreira da Rosa; Maria Célia Barcellos Dalri; Renato Barroso Pereira de Castro; Renzo Eduardo Cainelli Bianchi; Rita Márcia Rosa; Rosana Joaquim Fernandes; Rosemeire Aparecida de Oliveira Carvalho; Sílvia Maria Ribeiro; Tania Aparecida Cancian; Taísa Melo Monteiro.

PALS: Alessandra Kimie Matsuno; Alexander Dangio Engelberg; Ana Beatriz Gonçalves; Cláudia Bonafini Nóbrega; Claudia Dizioli Franco Bueno; Fábio Carmona; Helem Maira Pupin; Mônica Akissue Teixeira Cintra; Otávio Augusto Leite Cintra; Paulo Henrique Manso; Regina Maria Antunes Mattiello; Ricardo Kadri Monteiro; Rodrigo de Freitas Nobrega; Sílvia Regina Mançano; Simone de Oliveira Pillegi.

Pazin Filho A, Schmidt A, Filipini C, Castro RBP, Rosa RM, Rosa MAOF, Bueno CDF, Maciel BC. Patient simulation: life support courses ACLS, BLS and PALS in the Medical School of Ribeirão Preto of the University of São Paulo. Medicina (RibeirãoPreto) 2007; 40 (2): 204-12.

Abstract: The American Heart Association Life Support courses, including Basic Life Support, Advanced Cardiac Life Support and Pediatric Advanced Life Support, are spreading across the world since the introduction of international guidelines for clinical emergencies. The impact of the insertion of these courses on university institutions is unknown. The goal of this article is to describe the experience to implement these courses atthe University Hospital, Medical School of Ribeirão Preto, University of São Paulo (HCFMRP-USP), characterizing its historical evolution, impact onresearch, teaching and health care activities and also future perspectives.

Keywords: Advanced Life Support. Courses. Education, Medical. 


\section{REFERÊNCIAS}

1 - Timerman S, Gonzalez MM, Mesquita ET, Marques FR, Ramires JA, Quilici AP, et al. The International Liaison Committee on Resuscitation ILCOR). Roll in guidelines 2005-2010 for cardiopulmonary resuscitation and emergency cardiovascular care. Arq Bras Cardiol 2006;87(5):e201-8.

2 - White RD. 2005 American Heart Association Guidelines for Cardiopulmonary Resuscitation: physiologic and educational rationale for changes. Mayo Clin Proc 2006;81(6):736-40.

3 - Santos JS. Da fundação do Hospital das Clínicas à criação da Unidade de Emergência e sua transformação em modelo nacional de atenção hospitalar às urgências. Medicina (Ribeirão Preto) 2002;35(3):403-18.

4 - Santos J, Scarpelini S, Lopes S, Ferraz C, Dallora MELV, Sá MFS. Avaliação do modelo de organização da unidade de emergência do HCFMRP-USP, adotando, como referência, as políticas nacionais de atenção às urgências e humanização. Medicina (Ribeirão Preto) 2003;36(2/4): 498-515.

5 - Timerman S, Gonzalez MM, Zaroni AC, Ramires JA. Emergency medical services: Brazil. Resuscitation 2006; 70 (3): 356-9.

6 - Pazin-Filho A. Aula teórica: quando utilizar? Medicina (Ribeirão Preto) 2007;40 (1): 3-6.

7 - Pazin-Filho A. Tudo o que você sempre quis saber sobre aula téorica, mas ninguém teve coragem de te ensinar! Medicina (Ribeirão Preto) 2007;40 (1): 1-2.

8 - Pazin-Filho A, Scarpelini S, Schmidt A. Análise qualitativa da elaboração e apresentação de aulas teóricas por alunos de pós-graduação da FMRP-USP. Medicina (Ribeirão Preto) 2007;40 (1): 51-62.

9 - Pazin-Filho A. Espaço Aberto - A importância do treinamento de leigos para o atendimento da parada cardíaca. J SOCESP (Sociedade de Cardiologia do Estado de São Paulo) 2004; 8: 8

10 - Beckers S, Mueller M. Comparing apples and oranges. Crit Care Med 2006; 34(8):2263-4.

11 - Handler JA, Adams JG, Feied CF, Gillam M, Vozenilek J, Barthell EN, et al. Emergency medicine information technology consensus conference: executive summary. Acad Emerg Med 2004 11(11):1112-3.

12 - Jacobs I, Nadkarni V, Bahr J, Berg RA, Billi JE, Bossaert L, et al. Cardiac arrest and cardiopulmonary resuscitation outcome reports: update and simplification of the Utstein templates for resuscitation registries. A statement for healthcare professionals from a task force of the international liaison committee on resuscitation (American Heart Association, European Resuscitation Council, Australian Resuscitation Council, New Zealand Resuscitation Council, Heart and Stroke Foundation of Canada, InterAmerican Heart Foundation, Resuscitation Council of Southern Africa). Resuscitation 2004;63(3):233-49.
13 - Mennin S, Gordan P, Majoor G, Osman HA. Position paper on problem-based learning. Educ Health (Abingdon) 2003;16(1):98-113.

14 - Nolan JP, Hazinski MF, Steen PA, Becker LB. Controversial Topics from the 2005 International Consensus Conference on cardiopulmonary resuscitation and emergency cardiovascular care science with treatment recommendations. Resuscitation 2005 67(2-3):175-9.

15 - Moretti MA, Cesar LA, Nusbacher A, Kern KB, Timerman S, Ramires JA. Advanced cardiac life support training improves long-term survival from in-hospital cardiac arrest. Resuscitation 2007;72(3):458-65.

16 - Castro RBP, Pazin-Filho A, Schmidt A. Hipotermia acidental, choque elétrico e descargas por raios. Rev Soc Cardiol Estado São Paulo 2001;11(2):384-9.

17 - Pazin-Filho A, Castro RBP, Schmidt A. Cuidados pós-ressuscitação. Rev Soc Cardiol Estado São Paulo 2001;11(2):32834.

18 - Pazin-Filho A, Santos JC, Castro RBP, Bueno CDF, Schmidt A. Parada cárdio-respiratória (PCR). Medicina (Ribeirão Preto) $2003 ; 36: 163-78$.

19 - Pazin-Filho A, Pintya JP, Schmidt A. Distúrbios do ritmo cardíaco. Medicina (Ribeirão Preto) 2003;36:151-62.

20 - Pazin-Filho A. Morte: considerações para a prática médica. Medicina (Ribeirão Preto) 2005;38(1):20-5.

21 - Pazin-Filho A. Parada cardio-respiratória (PCR). In: Maciel BC, Marin-Neto JA, editors. Manual de condutas clínicas cardiológicas. 1 ed. São Paulo: Segmento Farma; 2005. p.193-205.

22 - Pazin Filho A. RCP para familiares e amigos. Rio de Janeiro: Associação Civil de Pesquisa e Desenvolvimento na Saúde;2001.

23 - Santos JC. Reanimação cardiopulmonar intra-hospitalar na Unidade de Emergências do Hospital das Clínicas da Faculdade de Medicina de Ribeirão Preto da Universidade de São Paulo. [Dissertação de Mestrado], Ribeirão Preto: Faculdade de Medicina de Ribeirão Preto - USP; 2006

24 - Santos JC, Pazin-Filho A, Schmidt A. Estudo epidemiológico do atendimento de paradas cardiorespiratórias em Hospital Universitário. Rev Bras Ter Intensiva 2004 (Supl I): A29.

25 - Santos JC, Pazin-Filho A, Schmidt A. Existe diferença na taxa de reversão de parada cardiorespiratória conforme o ritmo inicial? Registro de 390 atendimentos consecutivos em adultos. Rev Bras Ter Intensiva 2004 (Supl I): A29.

26 - Luciano PM. Registro dos distúrbios do ritmo cardíaco (DRS) atendidos na Unidade de Emergência do Hospital das Clínicas da Faculdade de Medicina de Ribeirão Preto da Universidade de São Paulo (UE-HCFMRP-USP). [Projeto de Pesquisa]. Ribeirão Preto: Faculdade de Medicina de Ribeirão Preto - USP. 